 Ciências Agrárias COINTER - PDVAgro 2017
}

\section{AVALIAÇÃO PARASITÁRIA EM SUÍNOS NA FASE DE TERMINAÇÃO CRIADOS NA LOCALIDADE DE JENIPAPO MUNICÍPIO DE UBAÍRA - BAHIA}

\author{
Apresentação: Pôster \\ Crislane de Souza Silva ${ }^{1}$; Gabrielle Mascarenhas Pereira ${ }^{2}$; Késila dos Santos Silva ${ }^{3}$; Fred da \\ Silva Julião ${ }^{4}$
}

\section{Introdução}

A suinocultura está difundida em todo o mundo e é uma das atividades da agropecuária de grande importância econômica e social. No Brasil a situação não é diferente, estando a suinocultura presente em todos os estados (THOMS et al., 2010). O país ocupa a quarta posição mundial em termos de produção e exportação de carne suína. Apenas em 2015 o Brasil exportou mais de 542 mil toneladas do produto, produzindo 3.643 toneladas no referido ano (ABPA, 2016).

Nas regiões brasileiras, a maior concentração destes animais está localizada na região sul (33\%), seguida das regiões nordeste $(28 \%)$, sudeste $(18 \%)$, norte $(11 \%)$ e centro-oeste $(10 \%)$. No Nordeste a criação de subsistência tem um importante papel social visto que uma parte da população depende do meio rural (D’ALENCAR et al., 2011).

Os suínos são animais de extrema importância econômica já que fornecem fonte alimentar e alternativas de renda. Estes animais podem ser criados confinados ou não (D'ALENCAR et al., 2011). Segundo ROPPA (2002), as atividades relacionadas à suinocultura ocupam lugar de destaque na cadeia produtiva do agronegócio brasileiro, estima-se que mais de 730 mil pessoas dependem diretamente da suinocultura, sendo essa atividade responsável pela renda de mais de 2,7 milhões de pessoas.

\footnotetext{
${ }^{1}$ Bacharelado em Zootecnia, Instituto Federal de Educação, Ciência e Tecnologia Baiano - Campus Santa Inês, criisifba@gmail.com

${ }^{2}$ Bacharelado em Zootecnia, Instituto Federal de Educação, Ciência e Tecnologia Baiano - Campus Santa Inês, gabimasper@gmail.com

${ }^{3}$ Bacharelado em Zootecnia, Instituto Federal de Educação, Ciência e Tecnologia Baiano - Campus Santa Inês, kesilazoo1991@gmail.com

${ }^{4}$ Orientador/Professor do Instituto Federal de Educação, Ciência e Tecnologia Baiano - Campus Santa Inês, fred.juliao@si.ifbaiano.edu.br
} 
Os parasitos representam um entrave na exploração suinícola, assim sendo, é necessário um maior conhecimento da epidemiologia das diversas espécies que afetam a estes animais, com o intuito de promover o melhor controle das parasitoses e garantir uma melhor qualidade do produto final (AGUIAR, 2009). Assim, o objetivo deste trabalho foi avaliar a ocorrência de endoparasitas em suínos na fase de terminação, criados na localidade de Jenipapo, município de Ubaíra - Bahia.

\section{Fundamentação Teórica}

Vários fatores influenciam na composição parasitária ou no nível de parasitismo dos animais, destacando-se: temperatura, umidade, susceptibilidade individual, idade dos animais, manejo, alimentação e tipo de criação. Os prejuízos causados pelas enteroparasitoses dependem do nível de contaminação ambiental que é influenciado pelo tipo de sistema de produção, pelas condições de higiene e as práticas de manejo (AGUIAR, 2009).

Os suínos são afetados por muitas espécies de parasitos, o que resulta em consideráveis perdas financeiras ao ano, devido ao crescimento lento, falha na conversão alimentar, aumento da susceptibilidade a outras doenças e condenação de órgãos no abate (TODD, BEHLOW e BATTE, 1992). Os endoparasitas comumente localizam-se no estômago e no intestino dos suínos, competindo com seu hospedeiro os nutrientes da alimentação consumida, causando irritação na mucosa do trato gastrointestinal, indigestão, falta do apetite, ulcerações no intestino, espoliação sanguínea interferindo no ganho de peso diário (HOFF et al., 2005).

Entre as principais espécies de parasitas que afetam os suínos podemos citar: Ascaris suum, Strongyloides ransomi, Globocephalus urosubulatus, Oesophagostomum dentatum, O. longicaudum, Trichuris suis, Metastrongylus salmi e Stephanurus dentatus, entre outros nematoides (D’ALENCAR et al., 2006; FOREYT, 2005). Protozoários também têm sido relatados em suínos, principalmente da classe dos coccídeos, que provocam quadros diarreicos intensos em leitões lactantes (PINTO et al., 2007).

A razão para a persistência do parasitismo nas unidades de criação é que a transmissão dos ovos e oocistos infectantes não é eliminada em todos os ambientes (CORWIN e TUBBS, 1993), sendo aconselhável promover medidas antiparasitárias e mantê-las em todos os estágios de criação dos suínos (JOACHIM e DAUGSCHIES, 2000).

\section{Metodologia}

O estudo foi realizado com suínos da raça Landrace e Large White, criados no sistema 
intensivo na localidade de Jenipapo, município de Ubaíra - BA, pertencente ao Vale do Jiquiriça. Os animais analisados em fase de terminação, são alojados em baias coletivas, cada uma contendo cinco suínos, com área de $15 \mathrm{~m}^{2}$, providos de comedouro tipo cocho e bebedouro do tipo chupeta.

Foram coletadas amostras fecais diretamente da ampola retal de suínos em duas propriedades. Essas amostras, foram armazenadas separadamente, identificadas e acondicionadas em caixa isotérmica refrigerada, a fim de conservá-las durante o trajeto até o Laboratório de Parasitologia do IF Baiano Campus Santa Inês, para a execução das análises parasitológicas, pela técnica Willis Mollay, a qual utiliza o princípio de flutuação e a técnica de sedimentação simples.

\section{Resultados e Discussões}

Nas cinco amostras analisadas de cada propriedade, conforme Tabela 1, constatou-se que na primeira propriedade apenas uma amostra deu resultado negativo para oocisto de Eimeria, através da técnica de Willis Molay. Com a técnica de sedimentação simples, verificou-se resultado positivo para ovos da família Strongyloidea e resultados negativos para ovos de Ascaris. Entretanto, na segunda propriedade as cinco amostras analisadas todas obtiveram resultados positivos para oocistos de Eimeria, apenas duas amostras de ovos de Ascaris e uma de ovos da família Strongyloidea.

Tabela 1: Resultados das análises fecais em suínos na fase de terminação. Fonte: Própria

\begin{tabular}{|c|c|c|c|c|}
\hline \multirow{6}{*}{ 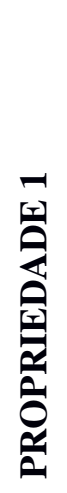 } & ANIMAL & $\begin{array}{c}\text { ASCARIS } \\
\text { SS }\end{array}$ & $\begin{array}{c}\text { EIMERIA } \\
\text { WM }\end{array}$ & $\begin{array}{c}\text { STRONGYLOIDEA } \\
\text { SS }\end{array}$ \\
\hline & 1 & - & - & + \\
\hline & 2 & - & + & - \\
\hline & 3 & - & + & - \\
\hline & 4 & - & + & - \\
\hline & 5 & - & + & - \\
\hline \multirow{5}{*}{ 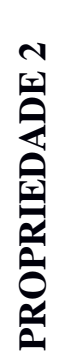 } & 1 & - & + & + \\
\hline & 2 & - & + & - \\
\hline & 3 & - & + & - \\
\hline & 4 & + & + & - \\
\hline & 5 & + & + & - \\
\hline
\end{tabular}

Esses resultados podem ser por manejo tradicional do rebanho com superlotação, pouca 
higienização, instalações precárias e deficientes programas de controle de parasitos instalados, encontrado nestas instalações (ROEPSTORFF e JORSAL, 1989). É importante verificar a vazão da água para que os dejetos sejam constantemente carregados do ambiente. Da mesma maneira, a frequência de limpeza das instalações com piso sólido por meio da remoção das fezes do ambiente é um fator determinante para a ocorrência destas parasitoses (NISHI et al., 2000).

Os resultados podem ser devido ao fato do padrão sócio econômico da criação de suínos por não permitir um plano de controle de doenças parasitárias, fator contrário ao da região oeste de Santa Catarina onde a produção de suínos e aves é a base do setor primário, com efetivos programas de controle das parasitoses CHARTIER et al. (1990), .

O controle parasitário depende muito mais da diminuição da exposição dos animais aos ovos e oocistos do que, de fato, da escolha do medicamento. Medidas preventivas incluem espaço apropriado nas baias, disponibilidade de água e alimentos sem contaminação, higienização continua do ambiente e divisão dos animais por categoria. Se algum animal estiver doente, deve ser isolado e tratado (HILLESHEIM e FREITAS, 2016).

\section{Conclusões}

Os animais avaliados apresentaram variedade de gêneros de endoparasitos, possivelmente devido às precárias condições de higiene e manejo a que estão submetidos, acarretando prejuízos ao produtor.

\section{Referências}

AGUIAR, P.C. Aspectos parasitológicos das parasitoses gastrointestinais de suínos naturalizados de criações familiares do Distrito Federal. 2009. 117p. Dissertação (Mestrado em Saúde Animal) - Universidade de Brasília, Brasília.

ASSOCIAÇÃO BRASILEIRA DE PROTEÍNA ANIMAL. Produção Mundial de Carne Suína. ABPA. 2014.

CHARTIER C.; MUTESI U. e NDAKALA N.O. Helminths of domestic pork in Ituri, Upper Zaire. Boreau du Projet Ituri, Bunia, Zaire. Sep; 70 (3):213-25. 1990.

CORWIN, R.M. e TUBBS, R.C. Common Internal Parasites of Swine. University of Missouri. 
1993.

D’ALENCAR, A.S.; FARIAS, M.P.O.; ROSAS, M.M.; LIMA, E.O.; ALVES, L.C.; FAUSTINO, M.A.G. Influência do manejo higiênico-sanitário na infecção por helmintos gastrintestinais em suínos de granjas tecnificadas e de subsistência abatidos na região metropolitana de Recife e Zona da Mata do estado de Pernambuco, Brasil. Arquivos do Instituto Biológico, São Paulo. v. 78, n. 2, p. 207-215, 2011.

D’ALENCAR, A.S.; FAUSTINO, M.A.G.; SOUSA, D.P.; LIMA, M.M.; ALVES, L. C.; RIBEIRO, T.C.F.S. Infecção por helmintos e coccídeos em criação de suínos de sistema confinado localizada no município de Camaragibe-PE. Ciência Veterinária nos Trópicos, v. 9, p. 79-86, 2006.

FOREYT, W. J. Parasitologia Veterinária: Manual de Referência. 5. ed. São Paulo: Roca, 2005. 248 p.

HILLESHEIM L. O.; FREITAS F. L. C. Occurrences of eimeriosis in calves reared on small family farms. Scientific report, v. 17, n. 3, 2016.

HOFF, G.; SILVA, A.S.; MONTEIRO, S.G. Avaliação do parasitismo e comparação de técnicas de analise fecal em suínos de granjas da região oeste do estado de Santa Catarina. Revista da FZVA. Uruguaiana, v. 12, n. 1, p. 106-115, 2005.

JESUS, L.P.; MÜLLER, G. Helmintos parasitos do estômago de suínos na região de pelotas, RS. Revista Brasileira de Agrociência, v. 6, n. 2, p. 181-187, 2000.

JOACHIM A. e DAUGSCHIES A. Endoparasites in swine in different age groups and management systems. Institut fur Parasitologie, Tierarztliche Hochschule Hannover. 113 (4): 12933. Apr. 2000.

NISHI S. M., GENNARI S. M., LISBOA M. N. T. S., SILVESTRIM A., JR L. C., UMEHARA O. Parasitas intestinais em suínos confinados nos estados de são paulo e minas gerais. 3 Arq. Inst. Biol., São Paulo, v.67, n.2, p.199-203, jul./dez., 2000.

PINTO, J.M.S.; COSTA, J.O; SOUZA, J.C.A. Ocorrência de endoparasitos em suínos criados em Itabuna, Bahia, Brasil. Ciência Veterinária nos Trópicos, v. 10, p. 79-85, 2007.

ROEPSTORFF A. e JORSAL S.E. Prevalence of helminth infections in swine in Denmark. Royal Veterinary and Agricultural University, Frederiksberg C, Denmark. v.33 ano.3, n.4, p.2319.Oct. 1989.

ROPPA, Luciano. Tendências da suinocultura mundial e as oportunidades brasileiras. ANUALPEC, 2002. p. 281-284.

THOMS, E.; ROSSA, L. S.; STAHLKE, E. V. R.; FERRO, I. D.; MACEDO, R. E.F. Perfil de consumo e percepção da qualidade da carne suína por estudantes de nível médio da cidade de Irati, PR. Revista Acadêmica: Ciências Agrárias e Ambientais, Curitiba, v. 8, n. 4, p. 449-459. 2010. 
TODD A.; BEHLOW R. e BATTE E. Health: internal parasites of swine. Colorado State University Cooperative Extension. Livestook series, nº 8007. oct. 1992. 